\title{
Study on the Control Indexes of Construction Land in Shandong Province from the Perspective of Intensive Use
}

\author{
Wang Hong ${ }^{1 *}$, Cui Dongxu ${ }^{2}$ \\ ${ }^{1}$ Jinan University, School of Civil Engineering and Architecture, Jinan, Shandong, 250022 \\ ${ }^{2}$ Shandong Jianzhu University, School of Architecture and Urban Planning, Jinan, Shandong, 250101
}

\begin{abstract}
Based on the revision of "Construction Land Control Standard of Shandong Province (2019)", this paper studied on the indexes of construction land of all kinds by improving the system of control standards, innovating the methods of studying the index, optimizing the content controlled by the index, etc., following the principle of land conservation and its intensive use. It is hoped that it can provide some reference for the establishment of a strict system of land conservation and its intensive use, effective implementation of land supply policies and industrial policies, and improvement of land use efficiency and resource protection capacity.
\end{abstract}

\section{Introduction}

With the rapid development of urbanization, high concentration of population and rapid expansion of construction land have become the general characteristics of cities and towns in our country. Moreover, extensive and inefficient use of land has been unbalancing the decreasing resource supply and increasing social demand. Under the circumstances, the state has fully clarified that "Intensive Development of Stock Land" is the only way to build a resource-saving society. Besides, The State Council's "Decision on Deepening Reform and Strict Land Administration" requires that the increase of construction land be strictly controlled, and efforts be made to revitalize the land stock and strengthen the economical use of land;The State Council "Notice on Promoting Economical and Intensive Land Use" clearly put forward to effectively protect cultivated land and ecological environment, promote the intensive use of land; The Ministry of Land and Resources "Urban and Rural Construction Land Increase and Decrease Link Pilot Management Measures", proposed that we should strengthen the urban and rural construction land increase and decrease link pilot work, in order to improve the quality of cultivated land, economical and intensive use of construction land;The Ministry of Land and Resources "Guidance on Promoting the Economical and Intensive Use of Land" clearly proposed that the scale of new urban construction land should be strictly checked and approved; "The Outline of the 13th Five-Year Plan of Land and Resources" has also clearly put forward the requirement of intensive use of land, which is to set the total amount, limit the capacity, enliven the stock, optimize the increment and improve the quality.
At present, there are some problems in land use, such as low efficiency of resource allocation, unreasonable structure of land use and so on. As a compulsory document for intensive use of land resources and reasonable guidance of urban construction layout, the standard for construction land is of great significance for social progress, economic development and ecological protection. Scholars have carried out a series of studies around the standard for construction land. Zhao et al. proposed the differentiated land use standards ${ }^{[1]}$; Feng et al. established a potential index system for land intensive use ${ }^{[2]} ;$ Zou proposed the urban development path of transformation from "incremental expansion" to "potential exploitation by stock" [3]; Tu et al. constructed the optimized strategy ${ }^{[4]}$; Huang et al. proposed the standard for per capita living space ${ }^{[5]}$; Xue et al. clarified the existing problems of the current standard ${ }^{[6]} ;$ Huang et al. discussed the issue of promoting intensive land use ${ }^{[7]}$; $\mathrm{Hu}$ et al. studied the implementation performance of interest reduction in industrial land renewal ${ }^{[8]}$; Liu et al. analyzed the theoretical basis for the reduction and growth of urban construction land ${ }^{[9]} ; \mathrm{Zu}$ et al. studied the evaluation system of intensive use of land ${ }^{[10]}$.

In this paper, the general thought and technical points of reasonable control of construction land scale mentioned in the revision of "Construction Land Control Standard of Shandong Province (2019)" is fully discussed. The revision has clearly proposed that intensive use of land resources is the direction of development, which is guided by the principles of optimizing the structure, activating the stock and improving the utilization efficiency, enhancing the connotation, controlling the total amount and increasing the decrement. Meanwhile, it can be achieved by some innovative methods, such as improving the system of

* Corresponding author's e-mail: wh2295738@sina.com 
control standards, innovating the methods of studying the indexes, optimizing the content controlled by the indexes and so on.

\section{Analysis of Land Use Problems in the Urbanization Stage}

2.1. The expansion of construction land is not synchronized with population growth, and the phenomenon of sharp decline of cultivated land is serious

First, the current expansion of urban construction land has not kept pace with population growth, but far exceeds the reasonable level.From 2000 to 2015, the growth rate of urban population was $59 \%$ and the built-up area was 113\%; Secondly, the construction occupation is the main factor of the sharp decrease of cultivated land, which directly threatens food security and ecological security. In 2017, 534,400 hectares of new construction land were added nationwide, and 320,400 hectares of cultivated land were reduced due to construction occupation, ecological conversion and agricultural structure adjustment; Thirdly, the phenomenon of "people decreasing and land increasing" in rural areas is prominent. From 2010 to 2016, the rural population decreased by 81.4 million, and the village land only decreased by 70,000 hectares.

\subsection{The land use structure is not coordinated with economic and social development, and the efficiency of resource allocation is low}

First, resource allocation pays less attention to the development of regional differentiation. The areas with high urbanization level have a high proportion of industrial land, while the supply of residential land and public service facilities for improving people's livelihood is insufficient; In areas with low urbanization level, the supply of land for energy, transportation and other infrastructure is insufficient; Secondly, the land use structure is insufficient to guarantee the urban functions. The planning pays attention to the urban function layout but lacks a more in-depth and detailed study on the land use structure;Thirdly, industrial land is growing too fast, many new development zones lack of industry and population agglomeration, and construction land is inefficient and idle.

\section{Revision Principles of Control Indexes Oriented by Intensive Use}

(1) The revision should adhere to the principles of optimizing the structure and improving the efficiency of resource allocation. In accordance with the relevant national standards and industrial norms, the resource conditions of Shandong province, all kinds of index should be adjusted to improve the standard system for construction land based on the resource conditions, the economic and social development, and the industrial development plans of Shandong province. Meanwhile, the land-use indexes for industrial projects should be tightened. The land-use indexes for public utilities should be relaxed. And the land-use indexes for some emerging industries should be increased.

(2) The revision should adhere to the principles of controlling the total amount and increasing the decrement. Both the total amount and intensity of construction land resources should be controlled. According to the total amount of construction land, the scale of cities, administrative towns and development zones should be well planned and controlled. The control of the indexes can help carry on the requirements of intensive use of land which is used for various construction projects. Moreover, it is clearly stipulated that the reconstruction and expansion projects shall make full use of the original sites and facilities. And the demand for new construction land should be minimized as far as possible.

\section{Revision of Control Indexes of Construction Land}

\subsection{Control Indexes of Regional Planning Construction Land}

Control indexes of construction land of cities: In the revision, the two control indexes, "planning per capita urban construction land" and "planning per capita single urban construction land", are used to improve their operability. In addition, the scale of the range as well as the allowable adjustment range of "planning per capita urban construction land" should be restricted.

Control indexes of construction land of administrative towns: In the revision, the index of construction land of administrative towns are determined by the per capita construction land index and the proportion of construction land set mentioned in "Planning Standard for Towns". The per capita construction land index is the average of the planning area of construction land divided by the number of permanent resident population. The area of population statistics should be consistent with the scope of land statistics.

Control indexes of construction land of development zones. The development zones mentioned here are the national and provincial ones. Various control index should be determined by data analysis and experience. Moreover, the bottom line of the index should also be decided by the types of development zones and the investment intensity. The proportion of land used for industrial storage, road and traffic facilities, landscapes and squares is stipulated.

\subsection{Control Indexes of Industrial Land}

First, according to "The Notice of the Ministry of Land and Resources of the People's Republic of China on Adjusting the Grade of Land in Some Areas", the grade and classification of land shall be adjusted in the light of 
the administrative division in Shandong. Second, due to the full consideration of the land demand of different areas, the demand of the developed areas which are short of land should be strictly restricted while that of the developing areas can be relaxed on the basis of regulation and control. Third, the economic development of Shandong ranks among the best in the country, so the demand should be slightly raised on the basis of the national standard.

Two indexes, "control index" and "quota index", are used to control the land used for industrial projects. (1) As for the control index, the minimum standard is adopted to investment intensity, plot ratio, average output value per mu, average tax per mu, building coefficient, while the highest standard is adopted to the land proportion and green space rate of administrative offices and service facilities. (2) The quota index refers to the one of construction land used for projects. In the revision, quota indexes of each subcategory are decided to measure the scale of land according to "National Industries Classification".

\subsection{Indexes of Construction Land Used for Rural and Urban Residential Areas}

In the revision, per-capita construction land, per-household residential land and plot ratio are taken as the three control indexes. Based on locations, and geographic and geomorphic conditions, the lower limit standard for per-capita construction land and per-household residential land are set while the upper limit standard for plot ratio is decided.

Control indexes of land use of new rural communities are added. Urban agglomerated communities should carry out the requirements of the urban planning of the places where they are located. However, the index of per capita construction land of rural agglomerated communities is set according to geographic and geomorphic conditions. At the same time, per capita residential land area is used as the control index to ensure the allocation of public facilities. Net density of the covered area of the selected residential area is used as the control index to accurately reflect the level of development intensity and intensive use of residential land.

As for land used for urban residential construction, residential land is classified according to the number of floors of residential buildings. In addition, plot ratio and net density of the covered area of a residential area are used as the control indexes of building capacity for different types of residential land. It's explicitly stipulated that the planned plot ratio of residential projects should be more than 1.0. Moreover, the lower limit of the net density of the covered area of a residential area is specified.

\subsection{Indexes of Construction Land for Infrastructure Projects}

In accordance with the national land and resources management policy, the indexes mentioned in the revision are strictly controlled, and some of the indexes are restricted. The regulation and control of some industrial land use is appropriately flexible on the basis of reflecting the intensification of land use and technological advancement. First, the standard system for construction land for infrastructure projects has been revised and improved, as control indexes for two kinds of land use, which are transport infrastructure and other municipal infrastructure, have been stipulated. Second, land use indexes of regional and comprehensive facilities have been stipulated respectively according to the characteristics of infrastructure.

\subsection{Indexes of Construction Land for Public Service Facilities}

Among the types of land used in cities, the land used for business and service industry can maximize the land efficiency. So the lower limit of its plot ratio and the recommended land area are stipulated from the perspective of intensive land use. In the process of land transfer, the upper limit of the plot ratio of the land used for business and service industry should be restricted according to the local regulations of plot ratio as well as the land level. The difference of regional economic development should be considered to coordinate the indexes by the discount coefficient.

Among the types of land used for storage, the land used for logistics parks is divided into different categories. Investment intensity, logistics intensity and the scale of a park are used as control indexes. Besides, lower limits of investment intensity and logistics intensity are set as well. At the same time, the corresponding regulations of the proportion of the land used for logistics operation area, supporting administrative offices and living service facilities in a park are also made.

Among the land used for public administration and public service facilities, the indexes of the land used for education, health care and other public utilities are appropriately relaxed. Per capita land-use index of each student in kindergartens and general primary and secondary schools should be raised as well as the upper limit of plot ratio. Moreover, per-bed land index of large-scale general hospitals should also be raised while the plot ratio should be reduced. The land used for the facilities should be increased for the elderly, special schools, secondary vocational schools, etc.

\section{Conclusion}

The revision of the standards in the 2019 edition mainly emphasizes: (1) Improving the standard system for construction land in Shandong province and giving full play to its leading role; (2) Improving the efficiency of land resource allocation by upgrading the connotation and optimizing the structure, and scientifically giving consideration to social equity and land supply constraints; (3) The applicability of land standards should be further improved by strict and moderate control of construction land indexes. In this paper, the guiding principles and 
research contents of the revision of construction land-use control indexes were studied from the perspective of intensive use. We hope it can provide a technical basis for improving the land-use efficiency and ensuring the sufficiency of land resources.

\section{Fund Project}

1.National key research and development projects during the 13th five-year plan period "Classification and spatial optimization of village and town communities" (2019YFD1100801); 2. Soft science research project of the ministry of housing and urban-rural development "Research on the layout planning of residential and living facilities based on industry orientation - Take Jinan high-tech zone as an example"(2015-R2-023).

\section{References}

1. Zhao Min, Wang Jun. Reconstruction of Urban Planning and Construction Land Standards and Control System in China [J]. Journal of Urban Planning, 2007(6): 29-35

2. Feng Changchun, Cheng Long. Potential Evaluation of Stock Land Intensive Use in Old Urban Areas: A Case Study of Dongcheng District, Beijing [J].Urban Development Research,2010,17(7): 86-92.

3. Zou Bing. From "Incremental Expansion" to "Inventory Optimization" -- The Motivation and Path of the Transformation of Shenzhen City's Urban Master Planning [J].Planner,2013,9(5):5-10.

4. Tu Zhihua, Wang Xingping, Cheng Cuiping. Discussion on the Optimization and Improvement of Urban and Rural Construction Land Standard: from the Perspective of Planning Compilation and Management. [J]. Urban Development Research, 2013,20(9): 58-65.

5. Huang Minghua, Jiang Wei, Wang Yao, etc. Sunny City and Broadacre City: The Future Development of Urban Residential Land in China from the Perspective of the New Land Use Standard [J]. Urban Development Research,2014,21(5):66-72.

6. Xue Haiyan, Zhang Wangfeng, Chen Huailu, etc. A Comparative Study of New and Old Urban Land Classification and Planning and Construction Land Standards [J]. Modern Urban Studies, 2015(11): 69-75.

7. Huang Minen, Zeng Chunxia.Renewal of planning and design norms and thinking of intensive land use [J]. Planner, 2015,31(6):144-147.

8. Hu Yingjie, Lv Bin. Benefit reduction mechanism and performance analysis of industrial land renewal in China [J].Urban Development Research,2016, 23(4):61-66.

9. Liu Wei, Lu Ping, Xu Jinhe.Study on the Decrease and Growth of Urban Construction Land in Anhui Province [J]. Journal of Anhui Agricultural Sciences, 2016,44(19):28-29.
10. Zu Jian, Hao Jinmin, Ai Dong, et al. Study on Endogenous Dynamics and Evaluation of Intensive Utilization of Construction Land Based on Factor perspective. [EB/OL]. Peking University Journal of Science (Natural Science Edition) (2020-01-10). Https://doi. org/10.13209/J. 0479-8023.2020.006. 